\title{
Individual Differences in Information Integration During Moral Judgment
}

\author{
Donelson R. Forsyth \\ Virginia Commonwealth University
}

\begin{abstract}
An ethical ideologies model based on relativism and idealism was tested. Subjects judged the morality of an individual who produced a mildly or extremely positive or negative consequence by conforming to or violating a common moral norm. As predicted, an averaging model with differential weights accounted for situationists' (high relativism and idealism) and absolutists' (low relativism and high idealism) judgments; conformity to norms was discounted when the consequence was extremely negative or positive. In contrast, subjectivists' (high relativism and low idealism) judgments conformed to an averaging model; a mildly positive consequence lowered moral judgments of conforming actions, whereas a mildly negative consequence tended to raise moral judgments of nonconforming actions. Last, exceptionists' (low relativism and idealism) judgments were influenced equally by conformity and consequence. These individuals generally combined data in a strictly linear, additive fashion; the more positive the consequence or the greater the conformity of the action to a moral norm, the more positive the moral judgment.
\end{abstract}

Although a number of theories of individual differences in moral thought have been proposed recently (e.g., Hamilton, 1976; Hogan, 1973; Kelman \& Lawrence, 1972; Kohlberg, 1976; Rest, Cooper, Coder, Masanz, \& Anderson, 1974), Forsyth (1980) suggests that variations in ethical ideology stem from differences in idealism and relativism. In the extreme, some individuals idealistically assume that good consequences can, with the proper action, always be obtained. Others, in contrast, pragmatically assume that good is often mixed with bad. Furthermore, whereas highly relativistic individuals question the value of universal moral principles, those who adopt a less relativistic orientation emphasize the importance of universal moral rules like "Thou shalt not lie" when making judgments.

Individuals who are classified as high or low in idealism and high or low in relativism fall into one of four ethical ideologies. Ex-

Thanks are extended to Norman $H$. Anderson and several anonymous reviewers for their comments on earlier drafts.

Requests for reprints should be sent to Donelson $R$. Forsyth, Department of Psychology, Virginia Commonwealth University, 810 West Franklin Street, Richmond, Virginia 23284 tremely high scorers on both dimensions are labeled situationists because their rejection of fundamental principles (high relativism) combined with a desire to achieve positive consequences (high idealism) promotes a careful weighing of situational information in arriving at moral judgments. Absolutists, in contrast, are low in terms of relativism but high in idealism, and so they prefer actions that yicld positive consequences through conformity to moral absolutes. Subjectivists (high relativism/low idealism) reject moral rules, but they also feel that negative consequences cannot always be avoided. Last, exceptionists score low on both dimensions and therefore believe that moral rules should guide behavior but that actions yielding some negative consequences should not necessarily be condemned. Individuals who endorse different ideologies have been found to divaricate on many contemporary moral issues (e.g., euthanasia, homosexuality, abortion; Forsyth, 1980); when attributing responsibility after wrongdoing (Forsyth, 1981); when judging the ethics of psychological research (Forsyth \& Pope, 1984; Schlenker \& Forsyth, 1977); and in guilt reactions after engaging in immoral behavior (Forsyth \& Berger, 1982).

This research examines the information integration strategies utilized by individuals 
within each ethical ideology. Although several models of information processing have been applied to moral judgment processes in recent years (e.g., Birnbaum, 1972, 1973; Lane \& Anderson, 1976; Leon, 1980; Oden \& Anderson, 1971), a substantial amount of research has focused on the additive, averaging, and weighted averaging models (Anderson, 1974, 1981). Briefly, the additive model suggests that bits of information about the object or individual being judged combine in a linear fashion analogous to addition. Simplifying somewhat, an individual who is honest $(+3)$ earns a positive appraisal but not as high an evaluation as the individual who is both charitable $(+2)$ and honest $(+3)$. A second approach, an averaging (or weighted additive) model, agrees that information combines in a linear fashion but suggests that cognitive algebra requires averaging. Hence, the individual who is simply honest scores higher than the individual who is both charitable and honest because +3 averaged with +2 is only +2.5 . The third approach, an averaging model with differential weights, predicts that information is still averaged together but that some of the items of information are weighted more heavily than others. For example, several models suggest that items with more extreme values are weighted more heavily (e.g., Anderson, 1981; Manis, Gleason, \& Dawes, 1966; Osgood \& Tannenbaum, 1955), and others suggest that the weight of any one bit of information depends on the value of any other available information (Anderson, 1971; Oden \& Anderson, 1971; also see Birnbaum \& Stegner, 1981; Surber, 1977, 1982).

The two-dimensional theory of ethical ideologies specifies two types of information, conformity of the action with moral principles and the quality of consequences, which must be integrated when making moral judgments. Therefore, these two variables were manipulated by asking subjects to make moral judgments about an individual who, by either conforming to or violating a moral principle, produced an extremely positive, mildly positive, mildly negative, or extremely negative consequence. Although we predicted that all subjects would generally be more approving of conforming rather than nonconforming behaviors and behaviors producing positive rather than negative consequences, differences between ethical ideologies were anticipated. First, situationists should be more strongly influenced by consequence data than the conformity of the action to a moral standard because they feel that (a) one should always strive to promote positive interpersonal outcomes (idealism) and (b) conformity to moral principles is not always possible (relativism). Furthermore, because only extreme consequences clearly violate or conform to situationists' values concerning human welfare and dignity, conformity to moral rules should be discounted even more when the consequences lead to extremely positive or extremely negative consequences. For example, whereas a mildly negative consequence (e.g., soiling someone's coat or breaking a fishing rod) may be seen as tolerable if caused by norm conformity, the impact of such a justification is minimal when the consequence involves loss of human life or psychological damage. Because the impact of one cue (conformity to norms) depends on the value of the second cue (consequence), these variables should interact as the averaging model with differential weights predicts.

Absolutists, in contrast, should be more influenced by the conformity cue rather than the consequence cue; actors who conform to moral norms should be positively evaluated, and those who violate moral norms should be condemned. Absolutists are also idealistic, however, and should be likely to excuse norm violations if the consequence that follows is extremely positive and to condemn normconsistent actions that yield an extremely negative consequence. Therefore, we predicted that an averaging model with differential weights would also describe absolutists' judgments but that the interaction between conformity and consequence cues would be due to absolutists' (a) less positive reaction to conforming actions that produce a highly negative consequence and (b) more positive reaction to nonconforming actions that produce a highly positive consequence.

Unlike their idealistic counterparts, subjectivists' and exceptionists' judgments should conform to a linear model of information integration. Whereas subjectivists should emphasize consequences more than conformity and exceptionists should emphasize confor- 
mity more than consequences, the low idealism of these two ideologies reduces the contextual impact of extreme consequences. Therefore, the two cues should be combined in a linear fashion, with positively valued cues (positive consequences and conformity to norms) contributing to a more positive evaluation and negatively valued cues (negative consequences and nonconformity to norms) contributing to a more negative evaluation. No specific predictions were advanced as to whether an additive or averaging model would best account for the low idealists' judgments, but both models were tested by examining the change in subjects' judgments when presented with two cues rather than one (Anderson, 1971).

\section{Method}

\section{Subjects}

The 32 men and 32 women who participated were recruited from introductory psychology classes at Virginia Commonwealth University. They were selected from a larger sample of approximately 325 individuals who completed the Ethics Position Questionnaire (EPQ) in a mass testing session (Forsyth, 1980). This scale measures ethical ideology with two 10 -item subscales. The first subscale taps ethical idealism with items like "A person should make certain that their actions never intentionally harm another even to a small degree" and "If an action could harm an innocent other then it should not be done." The ethical relativism subscale includes items like "Different types of moralities cannot be compared as to 'rightness" " and "What is ethical varies from one situation and society to another." Individuals respond to these items using a 9-point scale that ranges from completely disagree (1) to completely agree (9). Subjects who participated in the research scored 1 standard deviation above or below the median on both subscales and were classified as follows: (a) situationists: high idealism/high relativism; (b) absolutists: high idealism/low relativism; (c) subjectivists: low idealism/high relativism; and (d) exceptionists: low idealism/low relativism. Equal numbers of women and men were recruited for each ethical ideology, and all sessions were conducted by the same male experimenter.

\section{Procedure}

Conformity to moral rules cues. Subjects read a series of two-part sentences that described a stimulus person who caused positive or negative consequences by either conforming to or violating one of four moral principles dealing with theft, honesty, duty, and promises. The conformity of the action to a moral norm was manipulated in the first portion of the sentence by stating that the stimulus person either (a) stole something or did not steal something, (b) told a lie or the truth, (c) failed to do his or her duty or did his or her duty, or (d) kept or broke a promise. For example, the conforming cue read "because $X$ told the truth," and the nonconforming cue read "because X lied."

Consequences cues. The consequences of the action for an uninvolved third party (e.g., a child, a bystander, or a stranger) were manipulated in the second portion of the sentence. Four levels were established, including extremely positive (e.g., "A child's life is saved," "A little girl gets the life-saving operation she needs"); mildly positive (e.g., "A team wins a football game," "A child gets a free ticket to a movie"); mildly negative (e.g., "A passerby's coat gets dirty," "A fishing rod is broken"); and extremely negative ("A little boy loses his eyesight," "A passerby is horribly disfigured"). Thirty-two consequences ( 4 types of consequences $\times 8$ replicates) were utilized so that no consequence was ever used twice. Furthermore, any subject responded to one of eight different sets of standard conformity and consequences pairings; the administration of these pairings was counterbalanced across male and female subjects and the four ethical ideologies so that each set appeared only once in any cell.

Control cues. To tap the effect of conformity to the moral norm independent of consequences, subjects also responded to 8 cues that were presented without any consequence information. These sentences corresponded to the 2 (conformity vs. nonconformity to standard) $\times$ 4 (type of standard: theft, lying, failing to do one's duty, and breaking a promise) design.

Moral judgments. After reading a sentence, subjects responded to the item "How moral do you feel $X$ is?" by placing an $X$ on a 12-point scale ranging from immoral (1) to moral (12).

\section{Results}

\section{Manipulation Checks}

The conformity of the action variable was successfully manipulated. Five men and 5 women recruited from the same pool as the experimental subjects rated each action on a 12-point scale where 1 corresponded to incompatible with this society's standards of morality and 12 corresponded to compatible with this society's standards of morality. A $2 \times 2 \times 4$ (Sex $\times$ Conformity $\times$ Moral Standard) mixed analysis of variance (ANOVA) revealed a main effect of conformity, $F(1$, $8)=152.66, p<.05$. The nonconforming actions (e.g., a lie or a theft) were judged to be more incompatible than the conforming actions (e.g., telling the truth or not stealing); the respective means were 3.9 and 10.5 .

The consequences were also effectively manipulated, as indicated by the 10 judges' ratings of each of the 32 consequences on a 12-point bad (1) to good (12) scale. A $2 \times 4$ (Sex $\times$ Consequence) nested ANOVA yielded a significant main effect for outcome, $F(3$, 
Table 1

$F$ Ratios and Percentage of Variance Accounted for by the Main Effects and Interaction in the Analysis of Variance of Moral Judgments

\begin{tabular}{|c|c|c|c|c|c|c|}
\hline \multirow{2}{*}{$\begin{array}{l}\text { Ethical } \\
\text { ideology }\end{array}$} & \multicolumn{2}{|c|}{ Consequence main effect } & \multicolumn{2}{|c|}{ Conformity main effect } & \multicolumn{2}{|c|}{ Interaction effect } \\
\hline & $F$ & $\%$ & $F$ & $\%$ & $F$ & $\%$ \\
\hline Situationist & $100.69^{* * *}$ & 40.4 & $59.73^{* * *}$ & 35.6 & $6.12^{* *}$ & 2.0 \\
\hline Absolutist & $25.81^{* * *}$ & 18.2 & $49.92^{* * *}$ & 49.2 & $4.44^{*}$ & 1.3 \\
\hline Subjectivist & $71.75^{* * *}$ & 49.6 & $58.59^{* * * *}$ & 23.9 & 1.58 & 0.6 \\
\hline Exceptionist & $42.12^{* * *}$ & 30.5 & $39.60^{* * *}$ & 37.0 & 1.52 & 0.5 \\
\hline
\end{tabular}

${ }^{*} p<.01{ }^{* *} p<.001{ }^{* * *} p<.0001$.

$8)=82.14, p<.05$. The means, from extremely positive to extremely negative, were $11.5,9.3,3.9$, and 1.4 , respectively; all differed from one another by Duncan's multiplerange test $(p<.05)$.

\section{Moral Judgments: Group Analyses}

Altogether subjects responded to 40 items; 32 were generated by the $2 \times 4 \times 4$ (Conformity $\times$ Moral Standard $\times$ Consequence) design and 8 were additional control items. To simplify the analysis, responses were averaged across the four types of moral standards. These averages were found to possess high internal consistency; the average Cronbach alpha coefficient was .73. Preliminary analysis also revealed no consistent sex differences, so this variable was dropped in subsequent analyses.

Methods suggested by Anderson (e.g., 1974) were followed to test the descriptive power of the three alternative integration models. First, to test for nonlinear patterns, moral judgments for each ideology were submitted to a $2 \times 4$ (Conformity $\times$ Consequence) ANOVA. Both additive and averaging models predict only main effects; when plotted, the means across conditions should be parallel. However, the differential weights model predicts an interaction because the impact of the conformity-to-norm cue depends in part on the magnitude of the consequence. Second, if the interaction was nonsignificant, a $2 \times 5$ (Conformity $\times$ Consequence, including responses to the control stems) ANOVA was conducted to differentiate between the additive and averaging models. As Anderson has explained, if the interaction becomes significant when the control data are included, then the findings support the averaging model rather than the additive model (e.g., Anderson, 1981; Lane \& Anderson, 1976).

Situationists. As predicted, the consequence main effect far overshadowed the conformity main effect, although both reached significance and accounted for a substantial proportion of the variance (see Table 1). However, the interaction of conformity and consequence also reached significance and suggests a departure from linearity. The source of this interaction can be detected through inspection of Figure 1. The means in both the conforming and nonconforming conditions become increasingly positive as the consequence becomes more positive, but conforming to a standard has a greater impact on judgments when the consequence is mild rather than severe. For example, conformity raised the moral judgment by 4.3 points (from 5.6 to 9.9) when the consequence was mildly positive and by 4.9 points (from 4.0 to 8.9) when the consequence was mildly negative. However, conformity only raised the moral judgment by 2.9 points (from 2.8 to $5.5)$ when the consequence was extremely negative and by only 2.7 points (from 8.0 to $10.7)$ when the consequence was extremely positive. These findings suggest that the impact of the conformity cue depended on the magnitude of the consequence cue; they therefore support an averaging model with differential weights.

Absolutists. The judgments of subjects with this ideology were more strongly influenced by the conformity cue than the consequence cue. As shown in Table 1, both main effects were significant, but the confor- 


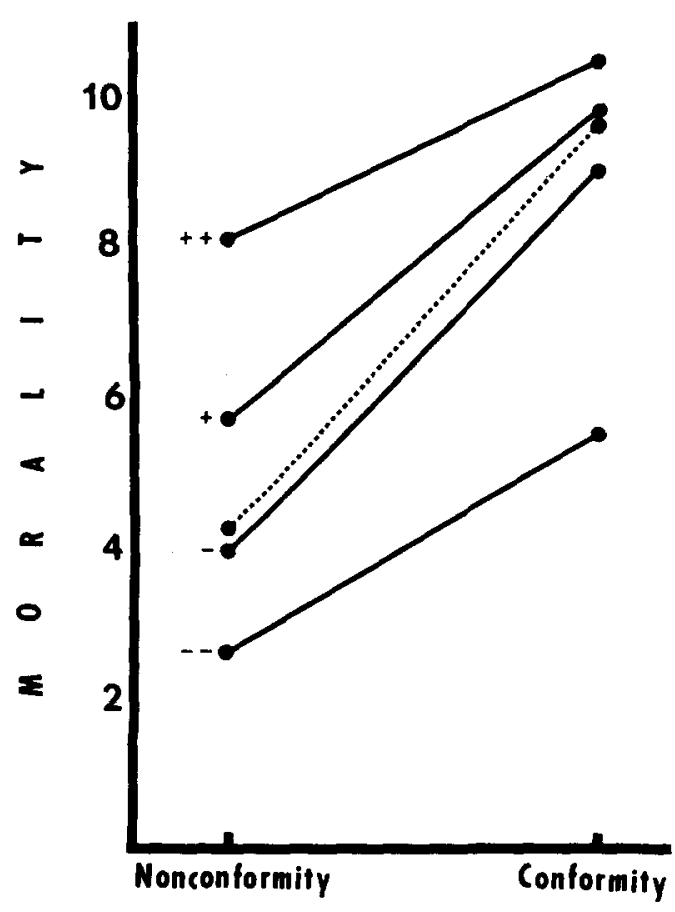

Figure 1. Situationists: An averaging model with differential weights. (The dotted line represents judgments of conforming and nonconforming actions without consequences.)

mity effect accounted for far more of the variance than the consequence main effect. However, the interaction also reached significance for absolutists. Like the situationists, absolutists were more favorable toward actions that conformed to a moral norm provided the consequence was not severely negative (see Figure 2). In addition, and to an even stronger degree than the situationists, absolutists were also more unfavorable toward nonconforming actions that produced a mild consequence or an extremely negative consequence. As shown in Figure 2, the means for only two of the conditions did not cluster with the others: conforming/extremely negative consequence and nonconforming/extremely positive consequence.

Subjectivists. Like situationists, subjectivists were more influenced by the consequence than the conformity cue (see Table 1). However, unlike situationists, only main effects reached significance in the $2 \times 4$ analysis, suggesting that a linear model describes subjectivists' judgments. Moreover, when the control items (judgments of the actions with no consequence information) were added in a $2 \times 5$ analysis, the interaction reached significance, $F(4,60)=7.83, p<.0001$. As shown in Figure 3, adding the control condition data produced a cross-over interaction that lends support to an averaging model. Following the logic suggested by Anderson (e.g., Lane \& Anderson, 1976), the dotted line represents the control condition and the solid line depicts judgments of actions yielding a mildly positive consequence. According to averaging theory, the solid line results from an averaging together of the mildly positive consequence information with the conformity/nonconformity data. Hence, when the actor breaks a moral norm, the positive consequence raises the average; however, when the actor conforms to the norm, the mildly positive consequence lowers the average.

Exceptionists. Unlike subjects with any of the other ideologies, and somewhat contrary to expectations, exceptionists weighted the two types of cues equally in formulating their

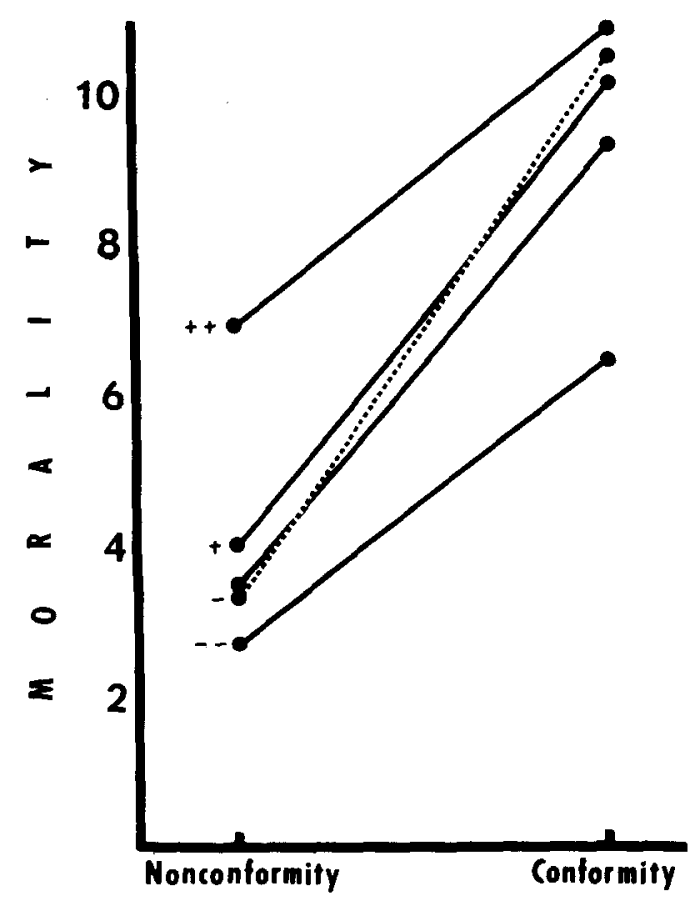

Figure 2. Absolutists: An averaging model with differential weights. (The dotted line represents judgments of conforming and nonconforming actions without consequences.) 


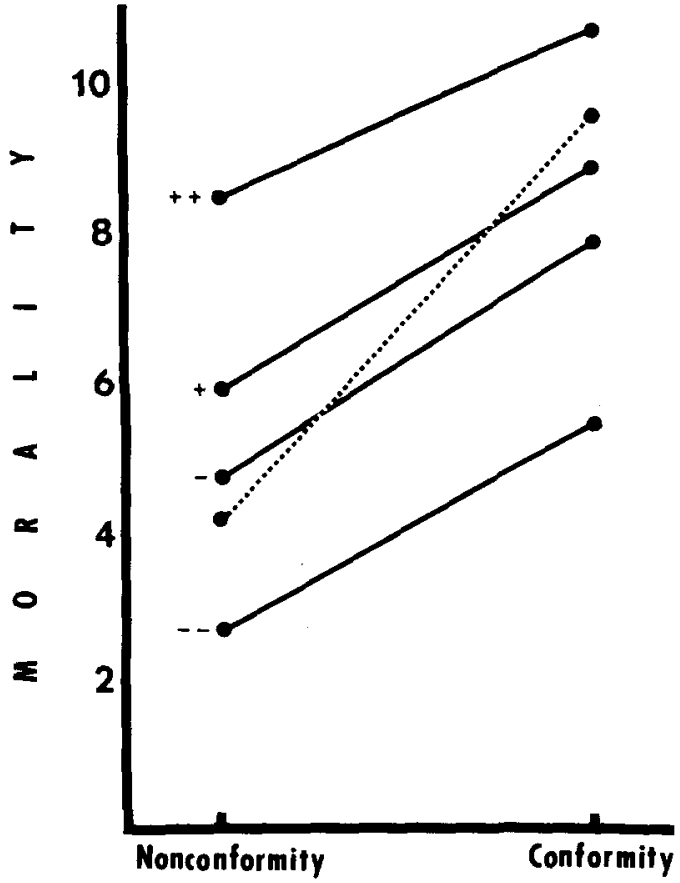

Figure 3. Subjectivists: An averaging model. (The dotted line represents judgments of conforming and nonconforming actions without consequences.)

moral judgments, although the conformity cue accounted for somewhat more of the variance. In addition, the main effects reached significance in both the $2 \times 4$ analysis (see Table 1) and the $2 \times 5$ analysis, but the interaction did not; the $F$ ratio for the interaction in the $2 \times 5$ analysis equalled 1.54 $(d f=4,60 ; p=.20)$. As shown in Figure 4, exceptionists' judgments showed strong evidence of the parallelism predicted by an additive model. Each cue seems to be integrated with the other cue in a cumulative, equally weighted fashion. The better the consequence, the more positive the moral judgment. The greater the conformity of the action to a moral norm, the more positive the moral judgment.

Contrasting the four ideologies. The differences among the four ethical ideologies were sufficiently pronounced to produce several significant interactions involving ideology, conformity to moral norms, and consequences when the data were examined in an overall $2 \times 2 \times 2 \times 4$ (Idealism $\times$ Relativism $\times$ Conformity $\times$ Consequence) repeated measures ANOVA. Confirming the differences between the two idealistic ideologies (situationists and absolutists) and the two pragmatic ideologies (subjectivists and exceptionists) reported above, the interaction between consequence, conformity, and idealism reached significance, $F(3,180)=3.15, p<.05$. As the means shown in Table 2 indicate, when the consequences were extreme, ideological differences were not very pronounced. (The only exception is the somewhat more negative judgment of individuals who produce a highly positive consequence through nonconformity). If, however, the consequence was mild, idealists were more favorable toward individuals who conformed to moral rules and less favorable toward nonconformists. These differences are consistent with the hypothesized use by situationists and absolutists of an averaging model with differential weights (see Surber, 1977, 1982).

The two-way interaction of relativism and conformity was also significant, $F(1,60)=$ $3.99, p=.05$. High and low relativists did not differ in their judgments of actors who

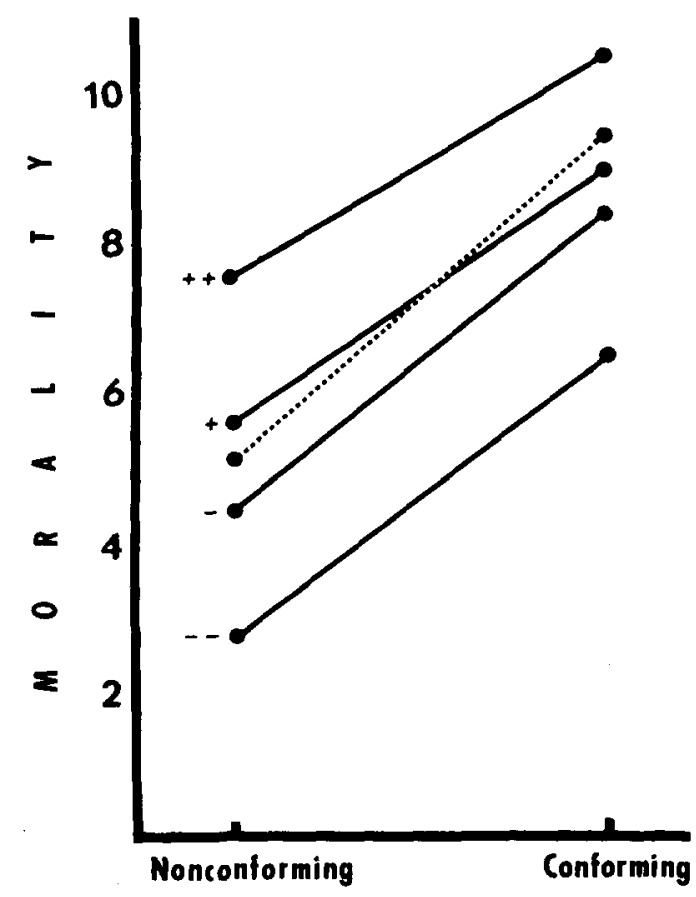

Figure 4. Exceptionists: An additive model. (The dotted line represents judgments of conforming and nonconforming actions without consequences.) 
Table 2

Moral Judgment Means for the Three-Way

Interaction of Idealism, Conformity to

Norms, and Consequences

\begin{tabular}{lcccccc}
\hline & \multicolumn{2}{c}{ High idealists } & & \multicolumn{2}{c}{ Low idealists } \\
\cline { 7 - 7 } \cline { 6 - 7 } Consequence & $\mathrm{C}$ & $\mathrm{NC}$ & & $\mathrm{C}$ & $\mathrm{NC}$ \\
\hline $\begin{array}{c}\text { Extremely } \\
\text { positive }\end{array}$ & $10.92_{\mathrm{a}}$ & $7.39_{\mathrm{c}}$ & & $10.47_{\mathrm{a}, \mathrm{b}}$ & $7.98_{\mathrm{d}}$ \\
$\begin{array}{c}\text { Mildly } \\
\text { positive }\end{array}$ & $10.01_{\mathrm{b}}$ & $4.82_{\mathrm{g}}$ & & $8.84_{\mathrm{c}}$ & $5.77_{\mathrm{f}}$ \\
$\begin{array}{c}\text { Mildly } \\
\text { negative }\end{array}$ & $9.06_{\mathrm{c}}$ & $3.75_{\mathrm{h}}$ & & $8.14_{\mathrm{d}}$ & $4.49_{\mathrm{g}}$ \\
$\begin{array}{c}\text { Extremely } \\
\text { negative }\end{array}$ & $6.11_{\mathrm{f}}$ & $2.46_{\mathrm{i}}$ & & $5.90_{\mathrm{f}}$ & $2.69_{\mathrm{i}}$ \\
\hline
\end{tabular}

Note $. \mathrm{C}=$ conforming; $\mathrm{NC}=$ nonconforming. Means that share a common subscript do not differ by Duncan's multiple range test $(p=.05)$.

conformed to moral rules $(M \mathrm{~s}=8.91$ and 8.45 , respectively), but high relativists (situationists and subjectivists) rated actors who violated moral rules more positively than did low relativists (absolutists and exceptionists; $M$ s $=5.23$ and 4.60 , respectively).

\section{Moral Judgments: Individual Analyses}

We also conducted separate $2 \times 4$ (Conformity $\times$ Consequence) ANOVAs for each individual subject; the 64 ANOVAs treated the judgments concerning the four moral standards (truthfulness, theft, duty, and promises) as replications, so the cell size for these analyses was 4 (see Birnbaum \& Stegner, 1981). As predicted, the interaction reached significance for $34.9 \%$ of the high idealists (11 of 32) but only $3.1 \%$ ( 1 of 32 ) of the low idealists, $\chi^{2}(1, N=64)=10.26, p<.05$.

Furthermore, when the proportion of variance accounted for by the interaction of conformity and consequence, for each subject, was examined in a $2 \times 2$ (Idealism $\times$ Relativism) ANOVA, a significant main effect of idealism was obtained, $F(1,60)=4.61, p<$ .05. The two-way interaction accounted for an average of $8.12 \%$ of the variance in the high idealists' judgments, but this same effect accounted for only $4.61 \%$ of the variance in low idealists' judgments. In addition, although no differences between ideologies were found in analyses of the consequence cue, differences between high and low relativists were obtained when the variance explained by the conformity cue was examined, $F(1,60)=6.80$, $p<.05$. This main effect accounted for more of the variance in moral judgments made by low rather than high relativists; the mean percentages were 41.80 and 25.86 , respectively. Last, the main effect of idealism was also significant when the total variance accounted for by the two main effects and the two-way interaction was examined, $F(1$, $60)=4.12, p<.05$. The manipulated independent variables accounted for an average of $78.73 \%$ of the variance in high idealists' judgments and $73.15 \%$ of the variance in low idealists' judgments.

\section{Discussion}

Two variables that should substantially influence moral judgments, the consistency of the action with moral rules and the kind of consequence generated by the action, were treated as personality variables as well as situational factors. As personality factors, these variables are the dimensions underlying the four-fold classification of ethical ideologies presented by Forsyth (1980). Individuals either accept or reject moral principles, and their orientation toward consequences is either idealistic or pragmatic. However, as situational factors, these two variables reflect the varying conformity of an action with a moral principle and the kind of consequence that is produced.

The overall findings suggest that the personality-level definition of these factors interacts with their situation-level definition to determine individual differences in moral judgments. Situationists, who are both relativistic and idealistic in their orientation toward consequences, are more strongly influenced by what the action produces than by the compatibility of the action with a moral standard. Absolutists, however, showed the opposite tendency; their nonrelativistic bent prompted them to focus more on moral rules than on consequences. These two types of judges, however, also displayed a tendency toward differentially weighting these variables when the consequence became extreme. Although the source of this similarity in information integration was not completely clarified in the current work, it may be that situationists first formulate their judgments 
on the basis of consequences, and then information about the conformity of the action with moral principles raises or lowers this judgment away from the anchoring point. The anchoring point for absolutists, however, is determined by the conformity data, and then consequences, if extreme, increase or decrease the favorability of the moral judgments. These mechanisms would account for the similarity in the two groups' judgments, the good fit of the differential weighting model, and previous findings that have indicated that absolutists are most condemning of violations of moral rules (Forsyth, 1980).

Like that of situationists, subjectivists' relativism prompted an increased focus on consequences over conformity to moral principles, but the variables were averaged together when the consequence was mild. Although this effect could result from situationists' assuming that a conforming action, when presented without any consequence information, leads to a mildly positive consequence (and that nonconforming actions generally lead to negative consequences), the findings are also consistent with an equal weights averaging approach. Although the averaging process should be investigated further by creating a continuum of conformity to moral norms as well as more levels of positive versus negative consequences, the basic findings suggest that (a) producing a mildly positive consequence through conformity will lead to a slightly less positive evaluation than will simply conforming to a moral principle and (b) producing a mildly negative consequence through nonconformity will lead to a slightly more positive evaluation than will simply violating a moral principle.

Exceptionists' judgments were somewhat more influenced by the conformity rather than the consequence information, as their nonrelativism would suggest, but the discrepancy was not large. Furthermore, these two factors seemed to be weighed equally when integrated in moral judgments, because the simplest information processing model of all, an additive approach, accounted for their judgments. Unlike subjects with any of the other ideologies, exceptionists seem to total up all the good aspects of the action, which can include conforming to moral rules and positive consequences, and subtract any bad aspects of the action, such as violating moral principles and producing negative consequences, to formulate an overall moral appraisal of action. This additive process, which may account for the greater favorability of exceptionists' judgments in previous research (Forsyth, 1981), requires further investigation, however, because (a) a slight cross-over pattern can be detected in Figure 4, (b) individuallevel analysis indicated that the interaction was significant for many of the exceptionists, and (c) the interaction $F$ ratio in the grouplevel analysis approached significance.

These findings also underscore the importance of taking into consideration individual differences when predicting moral judgments. Although previous research (e.g., Birnbaum, 1972, 1973; Lane \& Anderson, 1976) has suggested that the same model underlies all individuals' information integration strategies during moral judgment, different ethical ideologies appeared to be integrating information differently. The judgments of the two idealistic groups, situationists and absolutists, generally conformed to an averaging model with differential weights; the subjectivists showed a tendency to utilize an averaging procedure; and exceptionists' judgments were best predicted by an additive model. The data did not allow a crucial test of any of these three models. For example, the fit of the differential weights model could be explained with a configural model like that advocated by Birnbaum and his colleagues (e.g., Birnbaum, 1973; Birnbaum \& Stegner, 1981; Surber, 1982), and the averaging process shown by subjectivists may have been created by a contrast effect. However, at a minimum the data suggest that individuals vary in their cognitive information integration strategies and that these differences can be accounted for by taking into account their ethical ideology.

\section{References}

Anderson, N. H. (1971). Integration theory and attitude change. Psychological Review, 78, 171-206.

Anderson, N. H. (1974). Cognitive algebra. In L. Berkowitz (Ed.), Advances in experimental social psychology, 7 , 1-101.

Anderson, N. H. (1981). Foundations of information integration theory. New York: Academic Press.

Birnbaum, M. H. (1972). Morality judgments: Tests of an averaging model. Journal of Experimental Psychology, 93, 35-42. 
Birnbaum, M. H. (1973). Morality judgment: Test of an averaging model with differential weights. Journal of Experimental Psychology, 99, 395-399.

Birnbaum, M. H., \& Stegner, S. E. (1981). Measuring the importance of cues in judgment for individuals: Subjective theories of IQ as a function of heredity and environment. Journal of Experimental Social Psychology, 17, 159-182.

Forsyth, D. R. (1980). A taxonomy of ethical ideologies. Journal of Personality and Social Psychology, 39, 175184.

Forsyth, D. R. (1981). Moral judgment: The influence of ethical ideology. Personality and Social Psychology Bulletin, 7, 218-223.

Forsyth, D. R., \& Berger, R. E. (1982). The effects of ethical ideology on moral behavior. Journal of Social Psychology, 117, 53-56.

Forsyth, D. R., \& Pope, W. R. (1984). Ethical ideology and judgments of social psychological research: A multidimensional analysis. Journal of Personality and Social Psychology, 46, 1365-1375.

Hamilton, V. L. (1976). Individual differences in ascriptions of responsibility, guilt, and appropriate punishment. In G. Bermant, C. Nemeth, \& N. Vidmar (Eds.), Psychology and the law (pp. 239-264). Lexington, MA: Lexington Books.

Hogan, R. (1973). Moral conduct and moral character: A psychological perspective. Psychological Bulletin, 79, 217-232.

Kelman, H. C., \& Lawrence, L. H. (1972). Assignment of responsibility in the case of Lt. Calley: Preliminary report on a national survey. Journal of Social Issues, $28,177-213$.

Kohlberg, L. (1976). Moral stages and moralization: The cognitive developmental approach. In T. Likona (Ed.), Moral development and behavior: Theory, research and social issues (pp. 31-53). New York: Holt, Rinehart \& Winston.

Lane, J., \& Anderson, N. H. (1976). Integration of intention and outcome in moral judgment. Memory and Cognition, 4, 1-5.

Leon, M. (1980). Integration of intent and consequence information in children's moral judgments. In F. Wilkening, J. Becker, \& T. Trabasso (Eds.), Information integration by children (pp. 71-97). Hillsdale, NJ: Erlbaum.

Manis, M., Gleason, T. C., \& Dawes, R. M. (1966). The evaluation of complex social stimuli. Journal of Personality and Social Psychology, 3, 404-419.

Oden, G. C., \& Anderson, N. H. (1971). Differential weighting in integration theory. Journal of Experimental Psychology, 89, 152-161.

Osgood, C. E., \& Tannenbaum, P. H. (1955). The principle of congruity in the prediction of attitude change. Psychological Review, 66, 42-55.

Rest, J., Cooper, D., Coder, R., Masanz, J., \& Anderson, D. (1974). Judging the important issues in moral dilemmas. Developmental Psychology, 10, 491-501.

Schlenker, B. R., \& Forsyth, D. R. (1977). On the ethics of psychological research. Journal of Experimental Social Psychology, 13, 369-396.

Surber, C. F. (1977). Developmental processes in social inference: Averaging of intentions and consequences in moral judgment. Developmental Psychology, 13, 654 665.

Surber, C. F. (1982). Separable effects of motives, consequences, and presentation order on children's moral judgments. Developmental Psychology, 18, 257-266.

Received July 28, 1983

Revision received February 6, 1984 